López Vázquez, R., Tobón Tobón, S., Veytia Bucheli, M.G. y Juárez Hernández, L.G. (2021). Mediación didáctíca e inclusión educativa en la educación básica desde el enfoque socioformativo. Revista de Investigación Educativa, 39(2), 527-552.

DOI: http://dx.doi.org/10.6018/rie.443301

\title{
Mediación didáctica e inclusión educativa en la educación básica desde el enfoque socioformativo
}

\section{Didactic mediation and educational inclusion in basic education from the socioformative approach}

\author{
Rubén López-Vázquez*, Sergio Tobón Tobón**, María Guadalupe Veytia Bucheli*** \\ y Luis Gibran Juárez Hernández**** \\ *Dirección de Educación Especial. Secretaría de Educación Pública y Centro Universitario CIFE (México) \\ **Centro Universitario CIFE (México) \\ ***Facultad de Ciencias de la Educación. Instituto de Ciencias Sociales \\ y Humanidades. Universidad Autónoma del Estado de Hidalgo (México) \\ ****Centro Universitario CIFE (México)
}

\begin{abstract}
Resumen
Ante los retos del desarrollo social sostenible, es esencial fortalecer la inclusión en la educación básica con nuevos enfoques como la socioformación. Sin embargo, se desconocen los avances en la didáctica inclusiva en primaria, con base en este nuevo enfoque. Es por ello que el propósito del presente estudio fue determinar el grado de implementación de las prácticas de mediación didáctica inclusiva desde el enfoque socioformativo, con el fin de sugerir mejoras en este proceso a las escuelas. Acorde con esto, 689 docentes y 645 estudiantes de escuelas primarias públicas de México respondieron una rúbrica analítica compuesta por diez prácticas de mediación didáctica inclusiva. Esta rúbrica fue previamente validada con docentes y estudiantes. Cada práctica tuvo cinco niveles de desempeño, con base en la taxonomía socioformativa: preformal, receptivo, resolutivo, autónomo y estratégico. Los resultados muestran que hay un grado medio alto o alto en la implementación de la mediación didáctica inclusiva desde la socioformación, y esto fue superior en los docentes respecto a lo hallado en los estudiantes. La práctica de mediación
\end{abstract}

Correspondencia: Sergio Tobón, stobon5@gmail.com, Tabachin 51, CP 62141, Cuernavaca, Morelos, México. 
didáctica inclusiva más desarrollada fue el respeto a la diferencia y la menos desarrollada la evaluación formativa. Se concluye que los docentes tienen logros relevantes en la implementación de la mediación didáctica inclusiva, tomando como base la socioformación, pero esto debe ser tomado con precaución y se debe continuar con la mejora de este proceso mediante el trabajo colaborativo, la formación continua y la tutoría.

Palabras clave: Diagnóstico en educación; didáctica, diversidad; inclusión; mediación; rúbricas.

\section{Abstract}

Faced with the challenges of sustainable social development, it is essential to strengthen inclusion in basic education with new approaches such as socioformation. However, advances in inclusive didactics in primary schools are unknown based on this new approach. That is why the purpose of this study was to determine the degree of implementation of inclusive didactic mediation practices from a socioformative perspective, in order to suggest improvements in this process to schools. Accordingly, 689 teachers and 645 students from public elementary schools in Mexico responded to an analytical rubric composed of ten inclusive didactic mediation practices. This rubric was previously validated with teachers and students. Each practice had five levels of performance, based on the socioformative taxonomy: preformal, receptive, decisive, autonomous and strategic. The results show that there is a medium high or high degree in the implementation of inclusive didactic mediation from a socioformation perspective, and this was higher in the teachers than in the students. The most developed inclusive didactic mediation practice was that of respect for difference and the least developed was formative evaluation. It is concluded that teachers have relevant achievements in the implementation of inclusive didactic mediation, based on socioformation, but this must be taken with caution, and the improvement of this process must continue through collaborative work, continuous training and tutorships.

Keywords: Diagnosis in education; didacticism; diversity; inclusion; mediation; rubrics.

\section{Introducción}

Desde hace varias décadas se comenzó a incorporar la inclusión en la educación, bajo el planteamiento de que todos los estudiantes deben asistir a las mismas escuelas regulares, sin importar su condición respecto a la parte física, cognitiva, del aprendizaje o social (Gutiérrez y Martínez-Fernández, 2020; Liu et al., 2020). Desde entonces, se ha buscado que los estudiantes con dificultades para la formación, con discapacidad o que enfrentan barreras para el aprendizaje y la participación tengan las mismas oportunidades que los otros compañeros de su edad. Es así como la educación inclusiva ha tenido avances, y se ha convertido en una política en muchos países y un principio en la educación, buscando que todos los estudiantes reciban los apoyos necesarios para desarrollar sus potencialidades, y logren los aprendizajes necesarios para vivir en la sociedad en un marco de equidad (Ainscow et al., 2013; Ainscow, 2020; Martínez-Usarralde, 2021).

Para alcanzar un proceso educativo inclusivo es esencial que los directores, docentes, estudiantes, familias y comunidad se involucren en nuevos marcos teóricos, modelos, enfoques y metodologías educativas (Lleixà et al., 2015; Meroño et al., 
2019), que permitan orientar con claridad las diversas acciones que son necesarias para asegurar la formación integral en los estudiantes, considerando la planeación didáctica, la gestión de recursos, las acciones formativas, la evaluación, el seguimiento y el apoyo, partiendo de las características y procesos de participación y aprendizaje de los estudiantes (Jornet et al., 2020; Palencia et al., 2019; Parker et al., 2016; Rikkert et al., 2018). En este sentido, se tienen diferentes enfoques para abordar la inclusión. Los enfoques tradicionales se centran en lograr una cultura del respeto y aceptación de las diferencias o características personales, y estimular la participación (Sandoval et al., 2019), mientras que los nuevos enfoques como la socioformación, además de promover la cultura de respeto a las diferencias y buscar la participación, fomentan que cada uno de los actores que constituyen la escuela se formen de manera integral a través de la resolución de problemas o el logro de retos contextuales en el marco de proyectos colaborativos y transversales (De la Oliva et al., 2019).

La socioformación es un nuevo enfoque pedagógico, didáctico, curricular y evaluativo que se ha venido construyendo de manera colaborativa con las contribuciones de diversos actores educativos, tales como docentes, directivos, investigadores y expertos en educación. Busca formar en y para el desarrollo social sostenible por medio de la resolución de problemas y retos del entorno (Prado, 2018; Tobón y Luna-Nemecio, 2021), a través de proyectos, la colaboración, el proyecto ético de vida, la metacognición y la cocreación del conocimiento, en el marco de un trabajo participativo (Jarquin, 2019). Esto implica convertir las escuelas en microsociedades, que representen las fortalezas de la comunidad, pero también sus necesidades, y que el aprendizaje se lleve a cabo a través del mejoramiento de las condiciones de vida. Este enfoque es por esencia inclusivo, lo cual se logra al promover la participación de todos los actores de la escuela en la mejora de las condiciones de vida y el cuidado del ambiente, articulando las fortalezas, intereses, estilos de aprendizaje y recursos, en el marco de la aplicación de los valores universales. Esto implica que todos aportan para el logro de la meta establecida, y en esa medida, se apoyan y trabajan generando redes de colaboración y saberes colectivos.

En este sentido, desde el enfoque socioformativo, la inclusión fortalece el desarrollo social sostenible, el cual consiste en mejorar las condiciones de vida con base en la convivencia, el desarrollo económico, la colaboración, el desarrollo personal, el cuidado del ambiente y la protección de la biodiversidad (Luna-Nemecio, 2019a; 2019b; 2020). En este proceso la inclusión se enfoca en que todos los ciudadanos tengan las mismas oportunidades para vivir, desarrollarse e incrementar su calidad de vida con equidad, respetando las diferencias. Esto requiere un proceso de formación integral que posibilite afrontar los cambios en las diversas áreas, como la salud, la política, la economía, la convivencia, la educación, las Tecnologías de la Información y Comunicación (TIC), el ambiente, entre otras (Romera, 2016; Zapico et al., 2017), buscando la eliminación de barreras para el aprendizaje y la participación de los ciudadanos (Carrera-Fernández et al., 2018; Marín-Cepeda et al., 2017).

Lo anterior implica generar cambios en el sistema educativo para asegurar la inclusión, por medio de la aplicación de la socioformación, que implica el trabajo colaborativo entre todos los actores, el fortalecimiento de los valores universales y el abordaje de retos del contexto (De la Oliva et al., 2015; González, 2018; Jariot et al., 2020). Es por ello que, en la actualidad, la formación en las instituciones educativas debe ser inclusiva, y le compete 
a cada uno de los actores hacerla realidad (directores, docentes, estudiantes, padres y comunidad), de tal forma que todos los estudiantes se formen de manera integral para afrontar los retos de su contexto (De Haro et al., 2019; Lleixà et al., 2015; Pantić y Carr, 2017; Polo y Aparicio, 2018). Así, se favorece el acceso, la participación, el aprendizaje y el egreso oportuno de los estudiantes (Azorín et al., 2017; Cotán, 2019).

La inclusión solamente es posible si se trasciende la escuela tradicional orientada al aprendizaje de contenidos, bajo un modelo de organización industrial por objetivos y en serie (Jover y Luque, 2020; Tourón et al., 2018; Sanahuja et al., 2020a; Verdeja, 2018); y en su lugar surge una escuela socioformativa, en el marco de los retos del desarrollo social sostenible, que forme a los individuos con las actuaciones necesarias para afrontar los retos del entorno local, nacional y global, con base en la colaboración, el pensamiento complejo, la cocreación del conocimiento y el proyecto ético de vida, en la cual todos los actores trabajen con la visión compartida de mejorar las condiciones de vida cuidando el ambiente y la biodiversidad. Y esto debe darse en un entorno en el cual se busque que todos los participantes trabajen de forma articulada en el desarrollo del talento para afrontar los retos, algo que trasciende el mero reconocimiento a las diferencias o el acceso a oportunidades, que es la base de los enfoques tradicionales de la inclusión (De la Oliva et al., 2015; 2019).

De esta manera, aplicar la socioformación en las escuelas implica poner en práctica una diversidad de acciones, entre las que se encuentran las siguientes: 1) poner en acción la mediación didáctica centrada en resolver problemas con la participación de todos, a través de altas expectativas en su formación integral, respetando las diferencias (López et al., 2019; Sanahuja et al., 2020b); 2) asegurar el trabajo colaborativo y la práctica de los valores universales en todos los actores (Booth et al., 2015; Boroel et al., 2018; Sandoval et al., 2019; Tobón y Luna-Nemecio, 2021); 3) tener una cultura de respeto a la diversidad, mediante el reconocimiento y valoración de las diferencias en todos los participantes de la formación (Martínez et al., 2019; Montero y Gewerc, 2018); 4) aplicar estrategias didácticas por parte de los docentes que les permitan a todos los estudiantes lograr un aprendizaje pertinente y significativo (Anguita et al., 2018; Echeita, 2017; Escudero, 2019; Symeonidou, 2017; Zapico et al., 2017); 5) orientar la evaluación hacia el aprendizaje, la retroalimentación continua y la tutoría permanente, con acciones de apoyos diferenciados (Azorín, 2017; Bartau et al., 2017; Lleixà et al., 2015; Parker et al., 2016); 6) considerar los intereses, necesidades, estilos y ritmos de aprendizaje de los estudiantes a partir de un diagnóstico permanente (Esquivel, 2018; Hernández y Tobón, 2016; Miranda et al., 2019); 7) emplear recursos para la formación integral que se adapten a las características de todos los estudiantes (Booth et al., 2015); 8) buscar que los estudiantes tengan iniciativa y aborden retos entre sí, mediante la búsqueda de su formación (Ávila, 2017; Jover y Luque, 2020); 9) orientar y acompañar a todos los estudiantes (González et al., 2017; Symeonidou, 2017), dentro y fuera de las aulas, con la actitud y convicción de que todos poseen la capacidad de buscar, analizar, interpretar y resolver diversas situaciones del contexto, de tal manera que les permita transitar de un pensamiento de orden inferior a un pensamiento de orden superior (Parra-Acosta et al., 2017; Verdeja, 2018); y 10) apoyar a los estudiantes para que asuman un rol activo en la construcción de sus conocimientos, participando e involucrándose en los procesos de la mediación didáctica, aprendizaje y evaluación, 
sobre todo, que aprendan a asumir compromisos consigo mismo y con los demás, y a responsabilizarse de sus acciones para el logro de las metas educativas del currículo vigente (Aguilera, 2018; Carrasco et al., 2018).

Las escuelas en México poco a poco han venido avanzando en la incorporación de procesos de inclusión, y para ello se ha transitado por diversas etapas, desde la segregación, representada en tener diferentes tipos de instituciones, hasta la actual, en donde se ha avanzado en la cultura del respeto a la diferencia y el aprendizaje para todos. En este contexto, diversas instituciones educativas han optado por utilizar la socioformación en sus diferentes procesos a partir de la generación de diversas acciones entre las que se encuentran: 1) el diagnóstico de los avances en la inclusión; 2) la articulación de estrategias para disminuir las barreras para el aprendizaje y la participación en los planes de mejora continua; 3) la aplicación de estrategias didácticas centradas en retos colaborativos (Lee y Ávila-García, 2019); y 4) la formación de los docentes y directores en procesos de inclusión. Sin embargo, falta claridad en cuanto a los logros obtenidos a partir de la implementación de este enfoque y la percepción de los estudiantes sobre los avances en la didáctica, considerando la evaluación formativa. En algunos estudios se han encontrado beneficios de trabajar la socioformación en el proceso de inclusión, como por ejemplo el uso de rúbricas analíticas para el diagnóstico (Hernández-Ayala et al., 2020), el cambio de términos para favorecer un lenguaje inclusivo (De la Oliva et al., 2015) y la identificación del impacto de la intervención socioeducativa en los estudiantes (De la Oliva et al., 2019); sin embargo, no se ha evaluado el nivel de implementación de estrategias didácticas inclusivas y la percepción de éstas, por parte de los estudiantes, lo cual ayudaría a orientar de manera más adecuada los procesos de mejora en las escuelas.

Con base en lo anterior, el propósito del presente estudio es determinar el grado de implementación de la mediación didáctica inclusiva desde la socioformación en maestros de primaria, y establecer el grado en el cual los estudiantes perciben los avances de este proceso en las aulas. Para ello, se hará un diagnóstico descriptivo en un grupo de maestros que vienen implementando la socioformación en escuelas primarias públicas del sur de la Ciudad de México, con base en un proceso de formación continua, acompañamiento de directores y seguimiento y apoyo de asesores técnico-pedagógicos y supervisores. Por ende, se trata de un estudio postintervención, que busca establecer el impacto de la formación continua e implementar nuevas acciones de mejora.

\section{Método}

\section{Hipótesis}

Se hizo un estudio descriptivo de corte transversal y cuantitativo (Rodríguez y Caurcel, 2019), con el fin de contrastar las siguientes hipótesis:

Hipótesis 1. En los docentes de primaria, las prácticas de mediación didáctica inclusivas desde la socioformación son superiores al nivel de 4.0, medido con una rúbrica (los niveles y sus valores se muestran en la Tabla 3). 
Hipótesis 2. Los estudiantes de los últimos tres grados de primaria valoran las prácticas de mediación didáctica inclusiva desde la socioformación en un grado superior a 4.0, medido con una rúbrica.

Hipótesis 3. Los docentes de primaria autoevalúan las prácticas de mediación didáctica inclusivas en mayor grado que lo que hacen los estudiantes.

\section{Participantes}

La muestra estuvo conformada por 689 docentes y 645 estudiantes de los grados $4^{\circ}, 5^{\circ}$ y $6^{\circ}$ de educación primaria de escuelas públicas del sur de la Ciudad de México. En el grupo de docentes, el $46 \%$ fueron hombres y el 54.\% mujeres (Tabla 1). En el grupo de estudiantes, el 53\% correspondió a niños y el $47 \%$ a niñas (Tabla 1 ). Todos los participantes fueron de un nivel económico medio y casi todos viven en una zona urbana. Entre los docentes primaron los estudios de licenciatura y en las mujeres hubo un mayor porcentaje de estudios de maestría. En los maestros, la formación en procesos de inclusión fue de un 100\% lo cual se verificó a partir del registro de cursos de formación continua tomados en los últimos dos años (Tabla 2).

El tipo de muestreo empleado fue por conveniencia (no probabilístico). Los docentes se invitaron a participar a partir de diversas estrategias tales como: visita a centros de formación docente para invitar a los maestros a realizar la autoevaluación de sus prácticas pedagógicas de didáctica para la inclusión, lo cual en la investigación se ha encontrado positivo (García, 2018; Ford, 2018); visita a escuelas y envío de correos electrónicos. Además, se les pidió hacer la invitación a los estudiantes para que participaran en el estudio completando la rúbrica. El instrumento se aplicó en línea en docentes, mediante un formulario en Google Forms y en estudiantes de forma impresa. También es importante indicar que la aplicación de los instrumentos en las escuelas fue realizada con autorización de sus directores, a quienes previamente se les presentó el proyecto de investigación y sus beneficios para mejorar el apoyo a los docentes en la inclusión. Los instrumentos fueron aplicados con el apoyo de cuatro maestras especialistas en inclusión, quienes expusieron el proyecto en las escuelas y ayudaron a la aplicación con los estudiantes. Para realizar esta actividad, las maestras recibieron capacitación en el trabajo con rúbricas desde el enfoque socioformativo y se les explicó con detalle los propósitos de la investigación y los beneficios. También se les dio asesoría para manejar el componente ético, buscando que la información fuese confidencial y que los docentes y estudiantes participaran de manera libre.

\section{Tabla 1}

Datos sociodemográficos de los docentes y estudiantes

\begin{tabular}{lll}
\hline \multicolumn{1}{c}{ Características } & Docentes & Estudiantes \\
\hline \multirow{2}{*}{ Sexo } & Mujeres: $54 \%$ & Hombres: $53 \%$ \\
\multirow{2}{*}{ Promedio de edad } & Hombres: $46 \%$ & Mujeres: $47 \%$ \\
\hline
\end{tabular}




\begin{tabular}{lll}
\hline \multicolumn{1}{c}{ Características } & Docentes & Estudiantes \\
\hline Condiciones económicas & Nivel medio & Nivel medio \\
& Urbana: $93 \%$ & Urbana: $100 \%$ \\
\multirow{2}{*}{ Residencia } & Semiurbana: $4 \%$ & \\
& Rural: $3 \%$ & \\
\hline
\end{tabular}

Tabla 2

Datos profesionales de los docentes

\begin{tabular}{llll}
\hline \multicolumn{2}{c}{ Características } & \multicolumn{2}{c}{ Datos } \\
\hline Sexo & & Hombres: & Mujeres \\
\cline { 3 - 4 } & Estudios en la normal & $8 \%$ & $23 \%$ \\
Estudios & Licenciatura & $17 \%$ & $32 \%$ \\
& Maestría & $5 \%$ & $14 \%$ \\
Experiencia docente & Doctorado & $0 \%$ & $1 \%$ \\
Formación continua en & & 17.5 años & 20 años \\
inclusión & & $100 \%$ & $100 \%$ \\
\hline
\end{tabular}

\section{Instrumentos}

Rúbrica de Mediación Didáctica Inclusiva-Docentes. Esta rúbrica fue validada por López et al. $\left(2019^{*} ; 2020\right)$ y posee adecuados niveles de validez de contenido (valores en la V de Aiken superiores a 0.75 en las variables de pertinencia y comprensión para todos los ítems valorados), confiabilidad (Alfa de Cronbach de 0.967) y validez de constructo obtenido a partir de la aplicación del análisis factorial exploratorio. Está conformada por 10 prácticas pedagógicas basadas en el diseño y desarrollo de situaciones didácticas con el fin de promover la inclusión en los estudiantes. El propósito es que los docentes autoevalúen su metodología didáctica en las actividades que realizan con los estudiantes, para que determinen en qué nivel están logrando los aprendizajes esperados establecidos en el currículo, con base en el abordaje de retos del contexto. Cada práctica se valora mediante cinco niveles de desempeño (Tabla 3), y cada nivel se compone de descriptores basados en la taxonomía socioformativa (Sánchez-Contreras, 2019).

Rúbrica de Mediación Didáctica Inclusiva-Estudiantes. Esta rúbrica es similar a la primera, sólo que está adaptada a los estudiantes de los últimos grados de primaria. Comprende las mismas 10 prácticas pedagógicas orientadas a promover la inclusión en la mediación docente. Este instrumento fue también validado por López et al. (2020) y presentó validez de contenido a partir de la revisión de los expertos, pues se obtuvieron valores iguales o superiores a 0.75 en la $\mathrm{V}$ de Aiken en las variables de pertinencia y comprensión en las diez prácticas de mediación inclusiva abordadas. En este mismo estudio, los autores indican que la rúbrica posee validez de constructo con base en el análisis factorial exploratorio que hicieron y tiene una confiabilidad de 0.965 mediante el Alfa de Cronbach. 
Tabla 3

Síntesis de los niveles de desempeño en la taxonomía socioformativa

\begin{tabular}{|c|c|c|c|c|}
\hline \multicolumn{5}{|c|}{ Descriptores y niveles de desempeño } \\
\hline $\begin{array}{c}\text { Nivel I } \\
\text { Preformal } \\
(\text { Muy bajo=1) }\end{array}$ & $\begin{array}{l}\text { Nivel II } \\
\text { Receptivo } \\
(\text { Bajo=2) }\end{array}$ & $\begin{array}{c}\text { Nivel III } \\
\text { Resolutivo } \\
(\text { Medio=3) }\end{array}$ & $\begin{array}{c}\text { Nivel IV } \\
\text { Autónomo } \\
(\text { Medio alto=4) }\end{array}$ & $\begin{array}{c}\text { Nivel V } \\
\text { Estratégico } \\
(\text { Muy alto=5) }\end{array}$ \\
\hline $\begin{array}{l}\text { Desempeño } \\
\text { sin manejo } \\
\text { de nociones o } \\
\text { procedimientos }\end{array}$ & $\begin{array}{l}\text { Desempeño } \\
\text { mecánico } \\
\text { con nociones } \\
\text { elementales }\end{array}$ & $\begin{array}{l}\text { Desempeño } \\
\text { básico. Aplica } \\
\text { lo esencial con } \\
\text { comprensión } \\
\text { de la } \\
\text { información }\end{array}$ & $\begin{array}{l}\text { Desempeño } \\
\text { con análisis, } \\
\text { criterio y } \\
\text { argumentación. } \\
\text { Busca la eficacia } \\
\text { y eficiencia }\end{array}$ & $\begin{array}{l}\text { Desempeño con } \\
\text { liderazgo, vinculación, } \\
\text { interdisciplinariedad y } \\
\text { vinculación de saberes. } \\
\text { Afronta la incertidumbre } \\
\text { y el cambio con } \\
\text { estrategias y acciones } \\
\text { congruentes }\end{array}$ \\
\hline
\end{tabular}

\section{Procedimiento de recogida y análisis de datos}

Para realizar el análisis estadístico de los datos, se utilizó el programa JASP 0.14.1. (Goss-Sampson, 2018). Los procedimientos efectuados están de acuerdo con las hipótesis establecidas. En primer lugar, se analizó la normalidad de las variables en los docentes y estudiantes, con base en el empleo de la prueba Shapiro-Wilk. Al respecto, no se cumplieron los criterios de normalidad y se decidió usar la estadística no paramétrica para comprobar las tres hipótesis del estudio. En segundo lugar, se empleó la prueba de Wilcoxon $\mathrm{W}$ con el fin de determinar si había diferencias significativas respecto a la mediana teórica de 4.0, que en la rúbrica representa el nivel inicio del Autónomo, que es el nivel medio alto. Esto último se hizo tanto en los docentes como en los estudiantes. Los niveles de la rúbrica van de 1 a 5 , y se consideró en el equipo que la mediana debía ser 4.0 dado que el nivel mínimo en la inclusión es a partir del autónomo (Tabla 3). Para determinar valores bajos o altos también se empleó el procedimiento de la media más o menos una desviación estándar $[\mu \pm 1 \sigma]$, para identificar las prácticas mejor evaluadas $[\mu+1 \sigma]$ y las peor evaluadas $[\mu-1 \sigma]$ (Calderón et al., 2018). En tercer lugar, se determinó la existencia de diferencias significativas entre docentes y estudiantes respecto a cómo se está implementando la mediación didáctica inclusiva desde la socioformación en las escuelas, a partir del empleo de la prueba de Mann-Whitney para muestras independientes (Juárez-Hernández, 2018). En cuarto lugar, se calculó el tamaño del efecto de las diferencias entre docentes y estudiantes mediante la prueba de correlación de rango biserial, en correspondencia con la aplicación de la estadística no paramétrica. 


\section{Consideraciones éticas}

A todos los participantes, docentes y estudiantes, se les brindó información detallada del proyecto mediante reuniones presenciales, envío de información y correo electrónico. Se protegieron sus datos personales, de acuerdo con la Ley Mexicana de Protección de Datos Personales. También se les pidió a los participantes firmar un consentimiento informado y se les permitió retirarse en cualquier momento del estudio que se estaba llevando a cabo. Además, se conformó un comité de ética para revisar todos los aspectos éticos durante la investigación (Pineda et al., 2018).

\section{Resultados}

Hipótesis 1. En los docentes de primaria, las prácticas de mediación didáctica inclusivas desde la socioformación son superiores al nivel de 4.0, medido con una rúbrica.

En la Tabla 4 se presentan los valores de la prueba de Wilcoxon para una misma muestra tomando como mediana el valor de 4.0 que equivale al nivel autónomo o medio alto. Esto se muestra para cada una de las prácticas de mediación didáctica como también respecto a la medida total. Al respecto, puede observarse que todas las prácticas de mediación didáctica presentaron valores significativamente altos. Esto sugiere que la mayoría de los docentes de primaria que se autoevaluaron, implementan acciones que favorecen la inclusión desde el enfoque socioformativo, abordando la diversidad en el aprendizaje y los intereses, necesidades, cultura, lengua, estilos y ritmos de aprendizaje de los estudiantes. Sin embargo, cuando se analizan los valores inferiores y superiores tomando como criterio la media más o menos una desviación $(\mu \pm 1 \sigma)$, la práctica mejor evaluada fue 8: "Promuevo en el aula acciones para el reconocimiento y valoración de las diferencias de los estudiantes, como una oportunidad de aprendizaje, para favorecer la inclusión" y la práctica con menor valoración fue la 10: “Utilizo la evaluación para el mejoramiento continuo de los estudiantes, como una oportunidad de aprendizaje".

Tabla 4

Valores de las prácticas de mediación didáctica inclusiva desde la socioformación en los docentes ( $n=689$ )

\begin{tabular}{|c|c|c|c|c|c|}
\hline $\begin{array}{l}\text { Práctica de mediación } \\
\text { didáctica inclusiva desde } \\
\text { la socioformación }\end{array}$ & Media & $\begin{array}{l}\text { Desviación } \\
\text { estándar }\end{array}$ & Mediana & $\begin{array}{l}\text { Error } \\
\text { estándar }\end{array}$ & $\begin{array}{l}\text { Wilcoxon (a partir } \\
\text { de la mediana } \\
\text { teórica de } 4.0 \text { ) }\end{array}$ \\
\hline $\begin{array}{l}\text { 1. Inicio las clases } \\
\text { con una planeación } \\
\text { didáctica considerando } \\
\text { las características de los } \\
\text { estudiantes }\end{array}$ & 4.83 & 0.500 & 4 & 0.0190 & $175787^{*}$ \\
\hline
\end{tabular}




\section{Práctica de mediación \\ didáctica inclusiva desde \\ la socioformación \\ 2. Inicio las clases con una \\ introducción de lo que \\ aprenderán y realizarán \\ los estudiantes mediante \\ estrategias motivantes}

Media Desviación Mediana Error

Wilcoxon (a partir estándar estándar

4.82

0.570

4

0.0217

de la mediana

3. Aplico estrategias

4.84

0.513

4

0.0195

184495*

didácticas para

el desarrollo de

competencias de todos los

estudiantes

\section{Utilizo diversos}

4.83

0.510

$4 \quad 0.0194$

176965*

materiales didácticos

para el desarrollo de

aprendizajes significativos

de todos los estudiantes

5. Trabajo de forma

$4.84 \quad 0.531$

4

0.0202

$169934^{*}$

colaborativa para el logro

de las metas educativas y

favorecer la inclusión de

todos los estudiantes

6. Desarrollo las clases

a partir del abordaje y

0.550

4

0.0210

172568*

solución de un problema

del contexto mediante el

trabajo colaborativo

7. Diseño e implemento

$4.84 \quad 0.564$

4

0.0215

$178485^{*}$

proyectos innovadores

para desarrollar las clases

y favorecer la inclusión de

todos los estudiantes

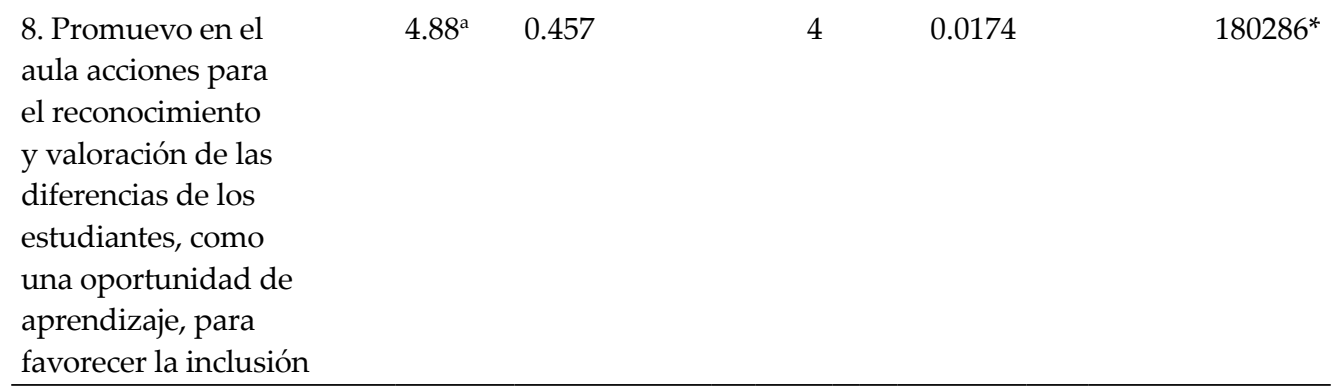




\begin{tabular}{|c|c|c|c|c|c|}
\hline $\begin{array}{l}\text { Práctica de mediación } \\
\text { didáctica inclusiva desde } \\
\text { la socioformación }\end{array}$ & Media & $\begin{array}{l}\text { Desviación } \\
\text { estándar }\end{array}$ & Mediana & $\begin{array}{l}\text { Error } \\
\text { estándar }\end{array}$ & $\begin{array}{l}\text { Wilcoxon (a partir } \\
\text { de la mediana } \\
\text { teórica de } 4.0 \text { ) }\end{array}$ \\
\hline $\begin{array}{l}\text { 9. Promuevo acciones en } \\
\text { el aula para impulsar la } \\
\text { formación en valores y el } \\
\text { crecimiento personal }\end{array}$ & 4.84 & 0.503 & 4 & 0.0191 & $168200^{*}$ \\
\hline $\begin{array}{l}\text { 10. Utilizo la evaluación } \\
\text { para el mejoramiento } \\
\text { continuo de los } \\
\text { estudiantes, como } \\
\text { una oportunidad de } \\
\text { aprendizaje }\end{array}$ & $4.76^{\mathrm{b}}$ & 0.591 & 4 & 0.0225 & $164392^{*}$ \\
\hline $\begin{array}{l}\text { Rúbrica general en los } \\
\text { docentes }\end{array}$ & 48.33 & 4.649 & 40 & 0.1771 & $237408^{*}$ \\
\hline
\end{tabular}

Nota: ${ }^{\star} \mathrm{p}<.001 ;$ a prácticas con mejor evaluación $(\mu+1 \sigma) ;{ }^{b}$ prácticas con peor evaluación $(\mu-1 \sigma)$

Hipótesis 2. Los estudiantes de los últimos grados de primaria valoran las prácticas de mediación didáctica inclusiva desde la socioformación en un grado superior a 4.0, medido con una rúbrica.

En la Tabla 5 se presenta el diagnóstico de las prácticas de mediación didáctica inclusiva desde la socioformación en los estudiantes. Esto se hizo por medio de la prueba de Wilcoxon para una misma muestra, tomando como mediana el valor de 4.0 que equivale al nivel autónomo o medio alto. Se presenta el análisis para cada una de las prácticas de mediación didáctica como también respecto a la medida total. $\mathrm{Al}$ respecto, puede observarse que todas las prácticas de mediación didáctica presentaron valores significativamente altos desde la evaluación de los estudiantes. Esto sugiere que los estudiantes reconocen los esfuerzos de los maestros por generar un clima de inclusión en las aulas. Sin embargo, cuando se analizan los valores inferiores y superiores tomando como criterio la media más o menos una desviación $(\mu \pm 1 \sigma)$ la práctica mejor evaluada fue "8. Tu profesor motiva la participación de todos los estudiantes en las clases para que trabajen respetando las diferencias de todos" y la práctica con menos valoración fue la 10: "Tu profesor utiliza la evaluación para el mejoramiento continuo, como una oportunidad de aprendizaje". Estos resultados son similares a los obtenidos en el grupo de los docentes. 
Tabla 5

Valores de las prácticas de mediación didáctica inclusiva desde la socioformación en los estudiantes ( $n=645)$

\begin{tabular}{|c|c|c|c|c|c|}
\hline $\begin{array}{l}\text { Práctica de mediación } \\
\text { didáctica inclusiva desde } \\
\text { la socioformación }\end{array}$ & Media & $\begin{array}{l}\text { Desviación } \\
\text { estándar }\end{array}$ & Mediana & $\begin{array}{l}\text { Error } \\
\text { estándar }\end{array}$ & $\begin{array}{l}\text { Wilcoxon (a partir } \\
\text { de la mediana } \\
\text { teórica de } 4.0 \text { ) }\end{array}$ \\
\hline $\begin{array}{l}\text { 1. Tu profesor inicia las } \\
\text { clases de acuerdo con una } \\
\text { planeación de actividades } \\
\text { considerando tus } \\
\text { características personales y } \\
\text { de tus compañeros }\end{array}$ & 4.7473 & 0.615 & 4 & 0.0242 & $150573^{*}$ \\
\hline $\begin{array}{l}\text { 2. Al iniciar las clases te } \\
\text { sientes motivado y sabes } \\
\text { qué realizarás durante el } \\
\text { día }\end{array}$ & 4.7302 & 0.668 & 4 & 0.0263 & $148649^{*}$ \\
\hline $\begin{array}{l}\text { 3. Tu profesor emplea } \\
\text { actividades con juegos } \\
\text { durante las clases para } \\
\text { que te motives y todos } \\
\text { aprendan }\end{array}$ & 4.7829 & 0.600 & 4 & 0.0236 & $158964^{*}$ \\
\hline $\begin{array}{l}\text { 4. Tu profesor utiliza } \\
\text { diversos materiales que } \\
\text { facilitan tu aprendizaje y la } \\
\text { de tus compañeros }\end{array}$ & 4.7767 & 0.608 & 4 & 0.0239 & $160341^{*}$ \\
\hline $\begin{array}{l}\text { 5. Tu profesor trabaja } \\
\text { en las clases de manera } \\
\text { colaborativa con todos } \\
\text { los estudiantes para que } \\
\text { aprendan con mayor } \\
\text { facilidad }\end{array}$ & 4.7876 & 0.620 & 4 & 0.0244 & $157605^{*}$ \\
\hline $\begin{array}{l}\text { 6. Tu profesor trabaja en } \\
\text { las clases a partir de la } \\
\text { solución de un problema } \\
\text { de tu comunidad }\end{array}$ & 4.7659 & 0.637 & 4 & 0.0251 & $153699^{*}$ \\
\hline $\begin{array}{l}\text { 7. Tu profesor trabaja } \\
\text { en las clases a partir } \\
\text { proyectos que logren } \\
\text { resolver problemas de tu } \\
\text { comunidad }\end{array}$ & 4.7705 & 0.666 & 4 & 0.0262 & $161240^{*}$ \\
\hline $\begin{array}{l}\text { 8. Tu profesor motiva la } \\
\text { participación de todos } \\
\text { los estudiantes en las } \\
\text { clases para que trabajen } \\
\text { respetando las diferencias } \\
\text { de todos }\end{array}$ & $4.8217^{a}$ & 0.544 & 4 & 0.0214 & $165828^{*}$ \\
\hline
\end{tabular}




\begin{tabular}{|c|c|c|c|c|c|}
\hline $\begin{array}{l}\text { Práctica de mediación } \\
\text { didáctica inclusiva desde } \\
\text { la socioformación }\end{array}$ & Media & $\begin{array}{l}\text { Desviación } \\
\text { estándar }\end{array}$ & Mediana & $\begin{array}{l}\text { Error } \\
\text { estándar }\end{array}$ & $\begin{array}{l}\text { Wilcoxon (a partir } \\
\text { de la mediana } \\
\text { teórica de } 4.0 \text { ) }\end{array}$ \\
\hline $\begin{array}{l}\text { 9. Tu profesor promueve la } \\
\text { formación en valores y el } \\
\text { crecimiento personal }\end{array}$ & 4.8062 & 0.586 & 4 & 0.0231 & $163833^{*}$ \\
\hline $\begin{array}{l}\text { 10. Tu profesor utiliza } \\
\text { la evaluación para el } \\
\text { mejoramiento continuo, } \\
\text { como una oportunidad de } \\
\text { aprendizaje }\end{array}$ & $4.6279^{b}$ & 0.738 & 4 & 0.0291 & $127489^{*}$ \\
\hline $\begin{array}{l}\text { Rúbrica General en los } \\
\text { Estudiantes }\end{array}$ & 47.62 & 5.494 & 40 & 0.2163 & $208335^{*}$ \\
\hline
\end{tabular}

Nota: * $\mathrm{p}<.001 ;$ a prácticas con mejor evaluación $(\mu+1 \sigma) ;{ }^{b}$ prácticas con peor evaluación $(\mu-1 \sigma)$

Hipótesis 3. Los docentes de primaria autoevalúan las prácticas de mediación didáctica inclusivas en mayor grado que lo que hacen los estudiantes.

En la Tabla 6 se describen las diferencias entre los docentes y estudiantes respecto al grado de aplicación de las diez prácticas de mediación didáctica inclusivas desde el enfoque socioformativo. Al respecto, se encontró que los docentes indicaron un mayor grado de aplicación de la mediación didáctica inclusiva que lo reportado por los estudiantes, debido a que hubo diferencias significativas en la medida global de la rúbrica aplicada $(\mathrm{p}<0.05)$. Respecto a las prácticas de mediación didáctica inclusiva, tomadas de manera separada, los docentes expresaron un mayor grado de aplicación de las siguientes prácticas respecto a lo que indicaron los estudiantes: 1. Planeación didáctica inclusiva, 2. Estrategias motivantes, 3. Estrategias didácticas aplicadas a todos los estudiantes y 10 Evaluación formativa inclusiva. Finalmente, el tamaño del efecto fue del 0.117 para la medida general de la rúbrica, que es un valor bajo, ya que se interpreta de la misma manera que se hace con la " $r$ " de Pearson (Goss-Sampson, 2018). Este valor bajo significa que, aunque hay diferencias entre docentes y estudiantes, el impacto no es relevante.

Tabla 6

Diferencias en las prácticas de mediación didáctica inclusiva en docentes $(n=n=689)$ y estudiantes de los últimos grados de primaria $(n=645)$

\begin{tabular}{|c|c|c|c|c|c|c|}
\hline \multirow{2}{*}{$\begin{array}{l}\text { Práctica demediación } \\
\text { didáctica } \\
\text { inclusiva desde la } \\
\text { socioformación }\end{array}$} & \multirow{2}{*}{$\begin{array}{l}\text { Mann- } \\
\text { Whitney } \\
\text { U }\end{array}$} & \multirow[t]{2}{*}{$\begin{array}{l}\text { Valor } \\
\text { de } p\end{array}$} & \multirow{2}{*}{$\begin{array}{l}\text { Estimación } \\
\text { de Hodges- } \\
\text { Lehmann }\end{array}$} & \multicolumn{2}{|c|}{$\begin{array}{c}\text { Intervalo de } \\
\text { confianza del } 95 \% \\
\end{array}$} & \multirow{2}{*}{$\begin{array}{l}\text { Tamaño } \\
\text { del } \\
\text { efecto** }\end{array}$} \\
\hline & & & & $\begin{array}{l}\text { Límite } \\
\text { inferior }\end{array}$ & $\begin{array}{l}\text { Límite } \\
\text { superior }\end{array}$ & \\
\hline $\begin{array}{l}\text { 1. Planeación didáctica } \\
\text { inclusiva }\end{array}$ & 211291 & $0.012^{*}$ & $1.275 e-5$ & $-4.14 e^{-5}$ & $2.60 \mathrm{e}-5$ & 0.0491 \\
\hline
\end{tabular}




\begin{tabular}{|c|c|c|c|c|c|c|}
\hline \multirow{2}{*}{$\begin{array}{l}\text { Práctica demediación } \\
\text { didáctica } \\
\text { inclusiva desde la } \\
\text { socioformación }\end{array}$} & \multirow{2}{*}{$\begin{array}{l}\text { Mann- } \\
\text { Whitney } \\
\text { U }\end{array}$} & \multirow[t]{2}{*}{$\begin{array}{l}\text { Valor } \\
\text { de } p\end{array}$} & \multirow{2}{*}{$\begin{array}{l}\text { Estimación } \\
\text { de Hodges- } \\
\text { Lehmann }\end{array}$} & \multicolumn{2}{|c|}{$\begin{array}{c}\text { Intervalo de } \\
\text { confianza del } 95 \%\end{array}$} & \multirow{2}{*}{$\begin{array}{l}\text { Tamaño } \\
\text { del } \\
\text { efecto }^{* *}\end{array}$} \\
\hline & & & & $\begin{array}{l}\text { Límite } \\
\text { inferior }\end{array}$ & $\begin{array}{l}\text { Límite } \\
\text { superior }\end{array}$ & \\
\hline $\begin{array}{l}\text { 2. Estrategias } \\
\text { motivantes }\end{array}$ & 209574 & $0.004^{*}$ & $1.365 e-5$ & $-4.82 e^{-5}$ & $1.45 e-5$ & 0.0568 \\
\hline $\begin{array}{l}\text { 3. Estrategias } \\
\text { didácticas aplicadas a } \\
\text { todos los estudiantes }\end{array}$ & 213607 & $0.034^{*}$ & $6.721 e-5$ & $-1.60 \mathrm{e}-5$ & $4.34 \mathrm{e}-5$ & 0.0387 \\
\hline $\begin{array}{l}\text { 4. Materiales } \\
\text { didácticos inclusivos }\end{array}$ & 215323 & 0.094 & $3.123 e-5$ & $-4.68 \mathrm{e}-5$ & $4.06 \mathrm{e}-5$ & 0.0310 \\
\hline $\begin{array}{l}\text { 5. Trabajo colaborativo } \\
\text { inclusivo }\end{array}$ & 216106 & 0.136 & $1.141 \mathrm{e}-5$ & $-6.94 \mathrm{e}-5$ & $5.18 \mathrm{e}-5$ & 0.0274 \\
\hline $\begin{array}{l}\text { 6. Resolución de } \\
\text { problemas con la } \\
\text { participación de todos }\end{array}$ & 214988 & 0.086 & $6.564 \mathrm{e}-5$ & $-2.02 \mathrm{e}-5$ & $2.23 e-6$ & 0.0325 \\
\hline $\begin{array}{l}\text { 7. Proyectos } \\
\text { innovadores } \\
\text { participativos }\end{array}$ & 214533 & 0.054 & $7.995 e-5$ & $-2.31 e^{-5}$ & $5.02 \mathrm{e}-5$ & 0.0345 \\
\hline $\begin{array}{l}\text { 8. Reconocimiento } \\
\text { y valoración de las } \\
\text { diferencias }\end{array}$ & 215721 & 0.089 & $1.919 e-5$ & $-1.61 e^{-5}$ & $3.09 \mathrm{e}-5$ & 0.0292 \\
\hline $\begin{array}{l}\text { 9. Formación } \\
\text { en valores y el } \\
\text { crecimiento personal }\end{array}$ & 219383 & 0.479 & $5.202 \mathrm{e}-5$ & $-1.36 e^{-5}$ & $2.54 \mathrm{e}-5$ & 0.0127 \\
\hline $\begin{array}{l}\text { 10. Evaluación } \\
\text { formativa inclusiva }\end{array}$ & 194386 & $<.001^{*}$ & $3.341 e-5$ & $8.11 \mathrm{e}-5$ & $3.84 \mathrm{e}-5$ & 0.1252 \\
\hline Rúbrica general & 196049 & $<.001^{*}$ & $7.632 e-5$ & $3.99 \mathrm{e}-6$ & $6.10 \mathrm{e}-5$ & 0.1177 \\
\hline
\end{tabular}

Nota: *diferencias significativas entre ambos grupos con $\mathrm{p}<0.05 ;{ }^{* *}$ el tamaño del efecto fue calculado mediante la correlación de rango biserial

\section{Discusión}

La primera hipótesis de este estudio se refería a que el grupo de docentes de primaria que participaron, tenían un nivel de desarrollo de las prácticas de mediación didáctica inclusiva desde la socioformación superior al grado de 4.0, referido al nivel Autónomo o medio alto. Al respecto, se encontró evidencia que permite comprobar esta hipótesis, dado que tanto la medida general como las medidas específicas en las prácticas de mediación mostraron niveles significativamente superiores a 4.0 (nivel autónomo) en la rúbrica aplicada, que era el nivel mínimo esperado para este grupo. En otros estudios también se han encontrado avances relevantes en la implementación de la mediación didáctica inclusiva por partes de los docentes, como, por ejemplo, Muntaner et al. (2016) y Rodríguez-Gómez et al. (2017), quienes refieren que los docentes tienen avances en conocer el entorno y las características y necesidades de los estudiantes, mediante la diversificación de estrategias y acciones. También se encuentra el estudio de Navarrete-Mendieta et al. (2020), quienes utilizan las 
aulas virtuales como mediación pedagógica para la inclusión y las discapacidades en el Ecuador. En general, las investigaciones previas señalan que la inclusión se logra paso a paso, a través de las contribuciones de diversos actores educativos, en lo cual los docentes tienen un papel esencial porque son ellos los que directamente están con los estudiantes y pueden generar un clima de trabajo participativo, que en la socioformación se hace a partir del abordaje de problemas del contexto o retos, considerando las necesidades de aprendizaje, los intereses y los estilos y ritmos de aprendizaje, mediante el trabajo colaborativo y la evaluación formativa continua (Muñoz y Marín, 2018; Parra-Acosta et al., 2017; Rappoport et al., 2019).

Respecto a la segunda hipótesis, referida a que los estudiantes que participaron en este estudio también consideran que el nivel de implementación de las prácticas de mediación didáctica inclusiva, son superiores al grado de 4.0, se halló evidencia que confirma esto. $\mathrm{Al}$ respecto, los estudiantes tuvieron valores significativamente superiores a la mediana de 4.0 (nivel autónomo en la rúbrica), tanto en la rúbrica general como en cada una de sus prácticas consideradas por separado. En otros estudios también se han hallado avances respecto a la inclusión valorados por los mismos estudiantes, como la investigación de Palma-Rojas (2017), que destaca los principios didácticos constructivistas como prácticas inclusivas en el aula de primaria. De igual manera, Mateus et al. (2017), hallaron que tanto los docentes como los estudiantes percibieron avances en la cultura y las prácticas inclusivas, a través de un estudio de métodos mixtos. Autores como Abellán y Sáez-Gallego (2020), De Haro et al. (2020), Muñoz y Marín (2018) y Rodríguez y Álvarez (2017), exponen que se forman prácticas más inclusivas cuando coexiste un auténtico compromiso con el trabajo, hay un vínculo de mejora con la autoestima del estudiante y se tiene pertenencia al contexto y estos aspectos se encuentran en los docentes y estudiantes que participaron en el presente estudio.

¿Qué factores explican los elevados niveles de prácticas de mediación didáctica inclusiva reportados por los docentes y estudiantes? Son posibles varias explicaciones. En primer lugar, las escuelas del sur de la Ciudad de México poseen un maestro o maestra especialista en inclusión, que orienta y acompaña a los directivos y docentes en actividades de inclusión con los estudiantes, implementando estrategias con quienes se encuentran en mayor riesgo de ser excluidos del proceso educativo (SEP-Autoridad Educativa Federal en la Ciudad de México [SEP-AEFCM], 2018). Esto no se encuentra en otros estados de la República Mexicana, en los cuales a lo sumo hay un maestro itinerante que atiende a varias escuelas y con frecuencia no puede hacer un adecuado proceso de formación, asesoría e intervención en una escuela concreta (SEP-Instituto de la Educación Básica del Estado de Morelos, 2018).

En segundo lugar, las escuelas vienen implementando de manera paulatina un nuevo enfoque pedagógico que es la socioformación, y esto puede estar ayudando a mejorar de manera significativa los procesos de inclusión en las instituciones que participaron en este estudio. La socioformación es un nuevo enfoque educativo que busca formar personas, grupos y comunidades para lograr el desarrollo social sostenible (Santoyo, 2019), por medio del afrontamiento de retos en el entorno con base en la colaboración y la inclusión. Para ello, se implementan proyectos colaborativos en los cuales participan todos los estudiantes, y a través de ellos se logra un proceso 
de inclusión real, en el cual todos se apoyan entre sí, para lograr los propósitos acordados. A medida que se participa en los proyectos para lograr un determinado reto, los estudiantes se apoyan, articulan sus fortalezas, se dan ánimo y se acompañan, con sus diferencias y semejanzas. Por consiguiente, en la socioformación la inclusión es parte de todas las estrategias que se implementan y es un componente central de su teoría. Al respecto, algunos estudios comienzan a mostrar los beneficios de la socioformación para fortalecer los procesos de inclusión, como por ejemplo el diagnóstico de la inclusión por medio del empleo de rúbricas (Hernández-Ayala et al., 2020); el cambio de algunos conceptos y términos propios de un enfoque clínico por una perspectiva más formativa (De la Oliva et al., 2015); y el impacto de la intervención socioformativa en las aulas (De la Oliva et al., 2019).

En tercer lugar, los docentes que participaron en este estudio se caracterizan por un alto compromiso con su formación continua. Al respecto, se pudo verificar a través de documentos oficiales que el $100 \%$ de los participantes, ha realizado al menos un curso de formación continua en los últimos dos años, y tienen capacitación en estrategias de inclusión. Esto puede ayudar a explicar los resultados positivos encontrados en el estudio, por cuanto son maestros que continuamente se están actualizando en esta área. Otros estudios muestran impacto de la formación continua en los docentes en el campo de la inclusión (Bedor-Espinoza, 2018; González-Gil, et al., 2017). Esto es debido al compromiso de los mismos directores de la zona en la cual se encuentran las escuelas (SEP-AEFCM, 2018).

Sin embargo, es factible que los resultados se deban a las características de los docentes que decidieron participar en el estudio (el muestreo fue no probabilístico), y no represente como tal, lo que está pasando en las escuelas a las que pertenecen. Al respecto, es posible que hayan decidido participar sólo aquellos maestros que se han formado en inclusión o que la están implementando de acuerdo con las prácticas de mediación descrita, y no los maestros que no se han formado en el área o no están aplicando estas prácticas. Por consiguiente, los resultados del presente estudio no pueden extrapolarse al sector sur de la Ciudad de México, ni mucho menos a toda la ciudad. También es posible que los resultados se deban a un temor de los maestros, de tener un posible rechazo si expresan que no aplican la mediación didáctica inclusiva, pues se trata de un propósito del sector educativo de las escuelas participantes en la presente investigación. Esta diferencia entre lo que se declara y lo que se hace se ha encontrado en otros estudios, como el de Muñoz y Otondo (2018), quienes hallaron que un grupo de docentes reportó que practicaba el constructivismo y la inclusión con los estudiantes, pero luego, a través de entrevistas en profundidad, se encontró que esto no era así.

Con respecto a los estudiantes, una explicación alternativa podría ser que los resultados no sean debido a prácticas reales de inclusión en las aulas, sino a un interés de responder de acuerdo con lo esperado por el director y los docentes (Herrera et al., 2018). Además, la inclusión es un tema muy sensible, y se espera que todos hablen bien de ella, que la practiquen, y que nadie se oponga. Por lo tanto, es factible que los estudiantes hayan respondido con niveles elevados, porque podrían pensar que eso ayudaría a sus maestros y directores o a la escuela (Veloquio, 2016). Aquí, es importante aclarar que en todo momento se indicó que se trataba de un estudio y que no tendría implicaciones negativas para la escuela, el director o los docentes. 
Un aspecto que destacar entre los docentes y estudiantes, es que hubo coincidencia en la práctica de mediación didáctica inclusiva que se considera más y menos desarrollada. La primera es el reconocimiento y valoración de las diferencias, y la segunda es la evaluación formativa. En diversos estudios se han encontrado avances respecto al reconocimiento y aceptación de las diferencias (González-Gil et al., 2017; Mateus et al., 2017; Miranda et al., 2019; Muntaner et al., 2016; Pinos y Velazco, 2021). El mayor desarrollo de esta práctica puede ser debido al énfasis que se ha tenido en la sociedad y el sistema educativo, de aceptar a todos, ya que antes había un alto grado de segregación (Bonilla-del-río et al., 2018; Muñoz-Borja et al., 2021; Rodríguez y Álvarez, 2017). Por otra parte, el tema de la evaluación formativa es un reto en la educación básica y de otros niveles educativos, porque todavía falta mucho para ser implementada (Asún et al., 2017; Ortiz et al., 2020; Rodríguez et al., 2018; SEP, 2018), y esto podría explicar el menor desarrollo de esta práctica en los docentes participantes del presente estudio. Otros autores también se han referido a la necesidad de fortalecer la evaluación inclusiva (Jara-Henríquez y Jara-Coatt, 2018; Muñoz y Marín, 2018), para formar de manera integral a los estudiantes (Bilbao y Villa, 2019; Chávez, 2019; De la Orden y Pimienta, 2016; Miranda et al., 2019). En la socioformación, esto es una prioridad, ya que se busca que la evaluación sea participativa, con base en la retroalimentación y el apoyo continuo a los estudiantes (Aguilar-Esteva y Acosta-Banda, 2020), por medio del trabajo con retos, la colaboración, los proyectos, el desarrollo de las habilidades de pensamiento complejo, la gestión del conocimiento y la metacognición.

Finalmente, respecto a la hipótesis tres, referida a la existencia de diferencias significativas entre docentes y estudiantes, la presente investigación también la pudo corroborar, y se halló que los docentes reportan mayores niveles de desarrollo en la medida general de prácticas de mediación didáctica inclusiva que los estudiantes, y también en cuatro prácticas concretas: planeación didáctica inclusiva, estrategias motivantes, estrategias didácticas aplicadas a todos los estudiantes y evaluación formativa inclusiva. En otros estudios también se han hallado diferencias entre los docentes y estudiantes respecto a las estrategias didácticas (Hidalgo y Perines, 2018; MartínezSilva y Martínez-Rojas, 2018) y la inclusión (Badia y Daura, 2018; Garnique-Castro y Gutiérrez-Vidrio, 2012), lo cual puede ser debido a diversos factores, tales como el contexto, la cultura, las actitudes, los comportamientos en el aula o los recursos que favorecen o limitan la inclusión de todo el estudiantado.

Respecto a las diferencias encontradas entre docentes y estudiantes a partir de la comparación de las medianas, es importante anotar que el tamaño del efecto no fue significativo para ninguna de las variables que se compararon, teniendo en cuenta que el tamaño del efecto se interpreta de forma similar a la " $r$ " de Pearson (Goss-Sampson, 2018). Por consiguiente, se puede plantear que, aunque hubo diferencias entre docentes y estudiantes, en la práctica el efecto es muy bajo y poco significativo. Por lo tanto, en términos del impacto, no es relevante la diferencia entre ambos grupos y esto hace que sea necesario considerar los estudios previos en los cuales no se han hallado diferencias entre los docentes y los estudiantes respecto a las prácticas de inclusión, como por ejemplo el realizado por Mateus et al. (2017).

¿Cuáles son los aspectos innovadores de la presente investigación? La presente investigación presentó una serie de aspectos innovadores para el contexto de Lati- 
noamérica, como los siguientes: 1) el análisis se enfocó en las prácticas de mediación didáctica, un tema poco abordado en sí mismo, ya que lo más común es estudiar este aspecto en el marco de las competencias docentes; las prácticas se orientan más a la actuación integral en contextos reales para que los estudiantes se formen y actúen en la mejora de las condiciones de vida y el cuidado del ambiente (Arreola et al., 2019) mientras que las competencias docentes se basan más en un conjunto de componentes o atributos para ejercer la enseñanza y el aprendizaje, como habilidades, conocimientos y actitudes; 2) el diagnóstico de la mediación didáctica inclusiva se hizo mediante el empleo de rúbricas analíticas, tanto en los docentes como en los estudiantes, mientras que en estudios recientes se han empleado escalas y cuestionarios (Pérez-Aranda et al., 2019), que tienen elementos de mayor subjetividad; y 3) el estudio se hizo en el marco de la aplicación de la socioformación en un grupo amplio de escuelas de primaria en el sur de la Ciudad de México, algo poco reportado en la literatura.

En futuros estudios se recomienda: 1) hacer registros de las clases, evaluar los recursos para el aprendizaje empleados y analizar las evidencias e instrumentos de evaluación, para contrastar la información suministrada por los docentes y estudiantes respecto a las prácticas de mediación didáctica inclusiva. Eso fue un vacío del presente estudio, ya que se enfocó en el autoinforme de docentes y estudiantes; 2) hacer un seguimiento longitudinal para verificar cuáles son los factores más asociados a la implementación de la mediación didáctica inclusiva desde la socioformación, y conocer el impacto de ésta en la formación integral y el logro de los aprendizajes esperados del currículo; 3) determinar el impacto de las prácticas de mediación didáctica inclusiva desde la socioformación en diversos indicadores de logro académico, como logro de los aprendizajes esperados que están en el currículo, abandono escolar, rezago, titulación, realización de las actividades de aprendizaje y entrega de las evidencias para la evaluación. Esto último faltó en la presente investigación; y 4) indagar a los directores, docentes de apoyo a la inclusión y padres de familia, además de los docentes y estudiantes, ya que son actores clave para lograr la inclusión en las escuelas.

También se brindan las siguientes recomendaciones a los directores, autoridades educativas y docentes en torno al fortalecimiento de la mediación didáctica inclusiva desde el enfoque socioformativo: 1) revisar la manera como se está brindando la evaluación formativa inclusiva, analizar el proceso, las evidencias, instrumentos e implementar mejoras que beneficien a todos los estudiantes en las escuelas; 2) conformar círculos de estudio y reflexión entre los docentes con el apoyo de un especialista en inclusión, para comunicar mejor el proceso a los estudiantes y tomar en cuenta sus sugerencias, con acciones de capacitación (Meroño et al., 2019; Symeonidou, 2017); 3) fortalecer el trabajo colaborativo entre los diferentes actores que intervienen en las escuelas, para ejecutar acciones que mejoren la inclusión, y esta tenga impacto en la formación integral y en el logro de los aprendizajes esperados de los estudiantes; 4) acompañar a los docentes con un desempeño bajo o medio en acciones para mejorar la inclusión con los estudiantes y fortalecer la práctica docente (Echeita, 2017; Lleixà et al., 2015; Parker et al., 2016; Sagredo et al., 2020); y 5) hacer círculos de estudio con los estudiantes en torno al fortalecimiento de la educación inclusiva, considerando sus sugerencias y dándoles un rol activo en la mejora de este proceso. 


\section{Referencias}

Abellán, J. y Sáez-Gallego, N. M. (2020). Opiniones relativas a la inclusión de los alumnos con necesidades educativas especiales mostradas por futuros maestros de infantil y primaria. Revista Complutense de Educación, 31(2), 219-229. https://dx.doi. org/10.5209/rced.62090

Aguilera, A. (2018). ¿Cómo valoran los estudiantes de magisterio la docencia que reciben? Revista Fuentes, 20(1), 57-75. http://dx.doi.org/10.12795/revistafuentes.2018. v20.i1.04

Aguilar-Esteva, V. y Acosta-Banda, A. (2020). Characterization of human talent evaluation from the traditional and socioformative approaches. Ecocience. International Journal, 2(2), 83-92. https://doi.org/10.35766/je20227

Ainscow, M. (2020). Promoting inclusion and equity in education: lessonsfrom international experiences. Nordic Journal of Studies in Educational Policy, 6(1), 7-16. https:// doi.org/10.1080/20020317.2020.1729587

Ainscow, M., Dyson, A. Goldrick, S. y West, M. (2013). Promoviendo la equidad en educación. Revista de Investigación en Educación, 11(3), 44-56. https://bit.ly/3omMFAV

Anguita, R., De la Iglesia, L. y García, E. (2018). Creación de contenidos transmedia en la sociedad hiperconectada. Una etnografía digital con jóvenes universitarios. Revista Fuentes, 20(1), 29-41. http://dx.doi.org/10.12795/revistafuentes. 2018.v20.i1.02

Arreola, A., Palmares, G. y Ávila, G. (2019). La práctica pedagógica desde la socioformación. Revista Argentina de Educación Superior, 18, 74-87. https://bit.ly/2MxquuJ

Ávila, E. F. (2017). 5. El Pensamiento Didáctico del Docente de Educación Inicial como elemento Reflexivo de la Práctica Pedagógica. EDUCARE, 20(2), 103-123. https:// goo.gl/vx6pHn

Azorín, C. M. (2017). Análisis de instrumentos sobre educación inclusiva y atención a la diversidad. Revista Complutense de Educación, 28(4), 1043-1060. https://doi. org/10.5209/RCED.51343

Asún, S., Rosario, M. y Chivite, M. (2017). Exploración de sistemas de evaluación formativa entre estudiantes universitarios en la provincia de Huesca. Apunts. Educación física y deporte, 127, 52-58. http://dx.doi.org/10.5672/apunts.2014-0983

Azorín, C. M., Arnaiz, P. y Maquilón, J. J. (2017). Revisión de instrumentos sobre atención a la diversidad para una educación inclusiva de calidad. Revista mexicana de investigación educativa, 22(75), 1021-1045. http://cort.as/-HEOJ

Badia, M. del M. y Daura, G. (2018). Evaluación e intervención educativa en el aula con alumnado disruptivo dentro del marco de una escuela. Inclusiva. Revista Educación, 42(2), 127-148. https://doi.org/10.15517/revedu.v42i2.24178

Bartau, I., Azpillaga, V. y Joaristi, L. M. (2017). Metodología de enseñanza en centros eficaces de la Comunidad Autónoma del País Vasco. Revista de Investigación Educativa, 35(1), 93-112. https://doi.org/10.6018/rie.35.1.225141

Bedor-Espinoza, L. P. (2018). La formación continua de los docentes para la inclusión de los estudiantes con necesidades educativas especiales. Espirales. Revista multidisciplinaria de investigación científica, 2(20). https://bit.ly/3osbKux

Bilbao, A. y Villa, A. (2019). Avances y limitaciones en la evaluación del aprendizaje a partir del proceso de convergencia. Visión docente y discente en los grados de 
Educación Infantil y Primaria. Educación XX1, 22(1), 45-69. https://doi.org/10.5944/ educXX1.19976

Bonilla-del-río, M., García-Ruiz, R. y Pérez-Rodríguez, M. (2018). La educomunicación como reto para la educación inclusiva. EDMETIC, 7(1), 66-86. https://doi. org/10.21071/edmetic.v7i1.10029

Booth, T., Simón, C., Sandoval, M., Echeita, G. y Muñoz, Y. (2015). Guía para la Educación Inclusiva. Promoviendo el Aprendizaje y la Participación en las Escuelas: Nueva Edición Revisada y Ampliada. REICE. Revista Iberoamericana sobre Calidad, Eficacia y Cambio en Educación, 13(3), 5-19. http://cort.as/-HEOa

Boroel, B., Sánchez, J., Morales, K. y Henríquez, P. (2018). Educación exitosa para todos: la tutoría como proceso de acompañamiento escolar desde la mirada de la equidad educativa. Revista Fuentes, 20(2), 91-104. http://dx.doi.org/10.12795/revistafuentes.2018.v20.i2.06

Calderón, A., Arias-Estero, J. L., Meroño, L. y Méndez-Giménez, A. (2018). Diseño y Validación del Cuestionario de Percepción del Profesorado de Educación Primaria sobre la Inclusión de las Competencias Básicas (\#ICOMpri3)”. Revista complutense de educación: Estudios sobre Educación. 34(19), 67-97. https://doi.org/10.15581/004.34.67-97

Carrasco, C., Alarcón, R. y Trianes, M. V. (2018). Adaptación y trabajo cooperativo en el alumnado de educación primaria desde la percepción del profesorado y la familia. Revista de Psicodidáctica, 23(1)1, 56-62. https://doi.org/10.1016/j.psicod.2017.02.001

Carrera-Fernández, M. V., Cid-Fernández, J. M., Antonio, A. A. y Lameiras-Fernadez, M. (2018). Actitudes hacia la diversidad cultural de adolescentes de secundaria españoles y portugueses: influencia de la heteronormatividad y la desconexión moral hacia el bullying. Revista de Psicodidáctica, 23(1) 17-25. https://doi.org/10.1016/j. psicod.2017.07.004

Chávez, M.P. (2019). Evaluación formativa dentro del proceso de inclusión educativa: realidad o discurso. En J. A. Trujillo-Holguín, A.C. Ríos-Castillo, y J.L. García-Leos (Coords), Desarrollo profesional docente: reflexiones de maestros en servicio en el escenario de la Nueva Escuela Mexicana. 117-133. Chihuahua, México. http://ensech.edu.mx/ pdf/maestria/libro4/TP04-2-04-Chavez.pdf

Cotán, A. (2019). ¿Es la universidad un entorno accesible? Historias de vida de estudiantes con discapacidad. Revista Fuentes, 21(1), 85-101. https:/doi.org/10.12795/ REVISTAFUENTES.2018.v21.i1.06

De Haro, R., Ayala, A. y Del Rey, M. V. (2020). Promoviendo la equidad en los centros educativos: identificar las barreras al aprendizaje y a la participación para promover una educación más inclusiva. Revista Complutense de Educación, 31(3), 341-352. https://doi.org/10.5209/rced.63381

De la Oliva, D., Tobón, S., Pérez, A. K. y Romero, J. (2015). The social inclusion process from the socioformation: Conceptual analysis to disability and Special Educational needs. Paradigma, 36(2), 49-73. https://bit.ly/3pEce1K

De la Oliva, D., Tobón, S., Pérez-Sánchez, A., Romero, J. y Escamilla-Posadas, K. M. (2019). Evaluación del modelo educativo constructivista de orientación educativa e intervención psicopedagógica desde el enfoque socioformativo. Educar, 55(2), 561576. https://doi.org/10.5565/rev/educar.772 
De la Orden, A. y Pimienta, J. H. (2016). Instrumento para determinar los tipos de evaluación utilizados por los profesores universitarios. Revista Electrónica de Investigación Educativa, 18(2), 40-52. http://goo.gl/rsT8Rf

Echeita, G. (2017). Educación inclusiva. Sonrisas y lágrimas. Aula Abierta, 46(2), 17-24. https://n9.cl/zegm

Escudero, T. (2019). Evaluación del profesorado como camino directo hacia la mejora de la calidad educativa. Revista de Investigación Educativa, 37(1), 15-37. http://dx.doi. org/10.6018/rie.37.1.342521

Esquivel, M. de la C. (2018). El proceso de integración de los niños a los talleres de creación artística de teatro y danza en la Casa de Cultura Pedro Junco, de Pinar del Río, Cuba. IE Revista de Investigación Educativa de la REDIECH, 9(16), 7-27. http:// cort.as/-JKSR

Ford, C. (2018). Effective practice instructional strategies: Design of an instrument to assess teachers' perception of implementation. Studies in Educational Evaluation, 56(0), 154-163. https://doi.org/10.1016/j.stueduc.2017.12.004

García, R. (2018). Diseño y construcción de un instrumento de evaluación de la competencia matemática: aplicabilidad práctica de un juicio de expertos. Ensaio: Avaliação e Políticas Públicas em Educação, 26(99), 347-372. https://doi.org/10.1590/ s0104-40362018002601263

Garnique-Castro, F. y Gutiérrez-Vidrio, S. (2012). Educación básica e inclusión: un estudio de representaciones sociales. Magis. Revista Internacional de Investigación en Educación, 4(9), 577-593. https://bit.ly/36rLOch

González-Gil, F., Martín-Pastor, E. y Begoña, B. (2017). ¿Están los futuros profesores formados en inclusión?: Validación de un cuestionario de evaluación. Aula Abierta 46, 33-40. https://doi.org/10.17811/rifie.46.2017.33-40

González, D., Olarte, F. y Corredor, J. (2017). La alfabetización tecnológica: de la informática al desarrollo de competencias tecnológicas. Estudios pedagógicos, 43(1), 193-212. http://dx.doi.org/10.4067/S0718-07052017000100012

González, M. de L. (2018). UVE socioformativa: estrategia didáctica para evaluar la pertinencia de la solución a problemas de contexto. IE Revista de Investigación Educativa de la REDIECH, 9(16), 133-153. http://cort.as/-JKQ0

Goss-Sampson, M.A. (2018). Análisis estadístico con JASP: una guía para estudiantes. Barcelona: UOC. https://bit.ly/3cmHLBE

Gutiérrez, M. F. y Martínez-Fernández, L. (2020). Representaciones sociales de docentes sobre la inclusión del estudiantado con discapacidad. Revista electrónica de investigación educativa, 22, 1-14. https://doi.org/10.24320/redie.2020.22.e13.2260

Hernández-Ayala, H., Tobón, S. T. y Juárez-Hernández, L. G. (2020). Estudio de validez de contenido y confiabilidad de un instrumento para diagnosticar el proceso de inclusión en las Escuelas Normales. Diálogos sobre educación, (22), 1-16. https://doi. org/10.32870/dse.v0i22.698

Hernández, H. y Tobón, S. (2016). Análisis documental del proceso de inclusión en la educación. Ra Ximhai, 12(6), 399-420. http://cort.as/-HEOq

Herrera, J. I., Parilla, Á., Blanco, A. y Guevara, G. (2018). La formación de docentes para la educación inclusiva. Un reto desde la Universidad Nacional de Educación 
de Ecuador. Revista Latinoamericana de Educación Inclusiva, 12(1), 21-38. https://bit. ly/36rvIzf

Hidalgo, H. y Perines, H. (2018). Dar voz a los protagonistas: La participación estudiantil en el proceso de enseñanza-aprendizaje. Revista Educación, 42(2), 438-464. https:// doi.org/10.15517/revedu.v42i2.27567

Jara-Henríquez, M. y Jara-Coatt, P. (2018). Concepciones y prácticas evaluativas declaradas por los docentes en respuesta a las necesidades educativas especiales de carácter permanente. Revista Latinoamericana de Educación Inclusiva, 12(2), 59-77. http://doi. org $/ 10.4067 / \mathrm{s} 0718-73782018000200059$

Jariot, M., Laborda, C. y González, H. (2020). El perfil competencial laboral de personas con discapacidad intelectual en centros ocupacionales. Revista de Investigación Educativa , 38(2), 475-493. http://dx.doi.org/10.6018/rie.312241

Jarquin, L. M. (2019). ¿Cómo generar docentes éticos mediante la Socioformación para lograr el Desarrollo Social Sostenible?. Ecocience International Journal, 1(1), 29-32. https://doi.org/10.35766/je19114

Jornet, J. M., Perales, M. J. y González-Such, J. (2020). El concepto de validez de los procesos de evaluación de la docencia. Revista Española de Pedagogía, 78(276), 233252. https://doi.org/10.22550/REP78-2-2020-01

Jover, G. y Luque, D. (2020). Relecturas de Paulo Freire en el siglo XXI. Cincuenta años de PEDAGOGÍA DEL OPRIMIDO. Educación XX1, 23(2), 145-164. https://doi. org/10.5944/educXX1.25640

Juárez-Hernández, L. G. (2018). Manual práctico de estadística básica para la investigación. Kresearch. https://doi.org/10.24944/isbn.978-1-945721-24-3

Lee, B. L. y Ávila-García, Y. (2019). Reflexiones en torno a los desafíos de la educación actual. Ecocience International Journal, 1(1), 24-28. https://doi.org/10.35766/je19113

Liu, Y., Bessudnov, A., Black, A. y Norwich, B. (2020). School autonomy and educational inclusión of children with special needs: Evidence from England. British Educational Research Journal, 46(3), 532-552. https://doi.org/10.1002/berj.3593

López, J., Fuentes, A. y Pozo, S. (2019). Educación Inclusiva e Intercultural al Borde de la Frontera: La Escolarización del Colectivo Mena. Revista De Pedagogía, 39(105), 173-196. https://n9.cl/hn7e

López, R., Tobón, S., Veytia, M. G. y Juárez, L. G. (2019*). Validación de dos instrumentos para evaluar el proceso de mediación en el aula para asegurar la inclusión educativa. Revista Dilemas Contemporáneos: Educación, Política y Valores, 0(3), artículo no. 22. https://doi.org/10.46377/dilemas.v24i3.1746

López, R., Tobón, S., Veytia, M. G. y Juárez, L. G. (2020). Validación de constructo de dos instrumentos para evaluar el proceso de mediación en el aula para favorecer la inclusión educativa. Revista Fuentes, 22(2), 1-12. https://doi.org/10.12795/revistafuentes.2020.v22.i2.04

Luna-Nemecio, J. (2019a). Para pensar la violencia, la migración y la educación como problemas sociales en el contexto de la crisis civilizatoria actual. Forhum International Journal of Social Sciences and Humanities, 1(1), 6-10. https://doi.org/10.35766/jf19111

Luna-Nemecio, J. (2019b). Hacia una nueva teoría del desarrollo social sosteniible basada en la multidisciplina, la complejidad y la socioformación. Human Development and Socioformation, 1(1), 1-13. https://bit.ly/3orrFcj 
Luna-Nemecio, J. (2020). Para pensar el desarrollo social sostenible: múltiples enfoques, un mismo objetivo. Kresearch. https://doi.org/10.35766/dss20

Lleixà, T., Capllonch, M. y González, C. (2015). Competencias básicas y programación de Educación Física. Validación de un cuestionario diagnóstico. Retos, (27), 52 - 57. https://doi.org/10.47197/retos.v0i27.34347

Marín-Cepeda, S., García-Ceballos, S., Vicent, N., Gillate, I. y Gómez-Redondo, C. (2017). Educación Patrimonial Inclusiva en OEPE: un estudio prospectivo. Revista de Educación, (375), 110-135. http://dx.doi.org/10.4438/1988-592X-RE-2016-375-337

Martínez, J. E., Tobón, S. y López, E. (2019). Currículo: un análisis desde un enfoque socioformativo. IE Revista de Investigación Educativa de la REDIECH, 10(18), 43-63. http://dx.doi.org/10.33010/ie_rie_rediech.v10i18.200

Martínez-Silva, M. y Martínez-Rojas, M. I. (2018). Hacia una didáctica en educar en y para la diversidad. En: M. Martínez-Silva (Coordinador), Educación Inclusiva en México. Avances, estudios, retos y dilemas, 92-111. https://bit.ly/39vWVCV

Martínez-Usarralde, M. J. (2021). Inclusión educativa comparada en UNESCO y OCDE desde la cartografía social. Educación XX1, 24(1), 93-115. http://doi.org/10.5944/ educXX1.26444

Mateus, L. E., Vallejo, D. M., Obando, D. y Fonseca, L. (2017). Percepción de las prácticas y de la cultura inclusiva en una comunidad escolar. Avances en Psicología Latinoamericana , 35(1), 177-191. https://doi.org/10.12804/revistas.urosario.edu.co/apl/a.4854

Meroño, L., Calderón, A., Arias-Estero, J. L. y Méndez-Giménez, A. (2019). Prediction model for the inclusion of key competences in the primary school curriculum through the teachers' perceptions in the Region de Murcia. Culture and Education, 31(1), 31-66. https://doi.org/10.1080/11356405.2018.1561108

Miranda, M., Burguera, J. L., Arias, J. M. y Peña, E. (2019). Inclusión, diversidad y equidad: diseño y validación de un cuestionario de opinión dirigido al profesorado de orientación educativa (IDEC-O). Revista de Investigación Educativa, 37(2), 505-524. https://doi.org/10.6018/rie.37.2.333891

Montero, L. y Gewerc, A. (2018). La profesión docente en la sociedad del conocimiento. Una mirada a través de la revisión de investigaciones de los últimos 10 años. Revista de Educación a Distancia, (56), 1-22. http://dx.doi.org/10.6018/red/56/3

Muñoz-Borja, P., Escobar, J., García-Ruiz, R. y Aguaded, I. (2021). Educomunicación inclusiva y discapacidad en la Región Andina: revisión cualitativa de avances y logros. Revista Complutense de Educación, 32(1), 67-78. https://doi.org/10.5209/ rced.68017

Muñoz, K. y Otondo, M. (2018). Evaluación de aprendizajes en estudiantes con necesidades educativas especiales. Revista Iberoamericana de Evaluación Educativa, 11(2). 71-90. https://doi.org/10.15366/riee2018.11.2.004

Muñoz, M. y Marín, R. (2018). Programa de inclusión en Educación Superior: experiencias de estudiantes en la Facultad de Medicina. Pensamiento Educativo. Revista de Investigación Educacional Latinoamericana, 55(1), 1-15. https://doi.org/10.7764/ PEL.55.1.2018.4

Muntaner, J. J., Rosselló, M. R. y De la Iglesia, B. (2016). Buenas prácticas en educación inclusiva. Educatio Siglo XXI, 34(1), 31-50. https://doi.org/10.6018/j/252521 
Navarrete-Mendieta, G., Guamán-Coronel, M. A., Arteaga-Marín, M. I. y GuamánCoronel, D.C. (2020). Aulas virtuales como mediación pedagógica para la inclusión y discapacidades. Publicaciones, 50(2), 31-39. https://bit.ly/3ciuNVE

Ortiz, E., Santos, J. M. y Marín, S. (2020). Evaluación continua en la enseñanza universitaria de la contabilidad. Revista de Investigación Educativa, 38(1), 109-129. https:// doi.org/10.6018/rie.329781

Palencia, V. C., Villagrá, S. L. y Rubia, B. (2019). Posibilidades y tensiones del docenteinvestigador en la escuela. El caso de Argentina, Brasil, Colombia y México. Revista Fuentes, 21(1), 115-134. https://doi.org/10.12795/REVISTAFUENTES.2018.V21.I1.08

Palma-Rojas, K. (2017). Los principios didácticos constructivistas como prácticas inclusivas en el aula de primaria. Innovaciones Educativas, 19(27), 41-54. https://bit. ly/2Mg4BQQ

Pantić, N. y Carr, D. (2017). Educating Teachers as Agents of Social Justice: A Virtue Ethical Perspective. Teacher Education for the Changing Demographics of Schooling. Inclusive Learning and Educational Equity, 2, 55-56. https://doi.org/10.1007/9783-319-54389-5_5

Parker, M., Patton, K. y O'Sullivan, M. ( 2016 ). Signature pedagogies in support of teachers' professional learning. Irish Educational Studies, 35(2), 137-153. https://doi. org/10.1080/03323315.2016.1141700

Parra-Acosta, H., Tobón, S., Juárez-Hernández, L. G., Lopez-Loya, J., Benavides-Olivera, J. G., García-Acosta, V. M., González-Ortiz, S., Carrazco-Palafox, J., Sánchez-Cañas, G. G. y Tobón, B. (2017). Teachers Recognize the Need to Develop Their Competencies to Improve Medical Students' Performance. International Journal of Environmental and Science Education, 12(8), 1895-1911. https://n9.cl/73g65

Pérez-Aranda, G. I., Gracia-Rejón, Y. M., y Estrada-Carmona, S. (2019). Socialización, edad y calificaciones en estudiantes con necesidades educativas especiales / Socialization, Age and Grades in Students with Special Educational Needs. RICSH Revista Iberoamericana de las Ciencias Sociales y Humanísticas, 8(15), 18-42. https://doi. org/10.23913/ricsh.v8i15.158

Pineda, C. A., Castro, J. A. y Chaparro, R. A. (2018). Estudio psicométrico de las Escalas de Bienestar Psicológico de Ryff en adultos jóvenes colombianos. Pensamiento Psicológico, 16(1), 45-55. http://goo.gl/aGrdze

Pinos, K. M. C. y Velazco, D. J. M. (2021). Estrategias y materiales didácticos digitales para estudiantes en educación infantil con diversidad de aprendizaje. Research, Society and Development, 10(1). https://doi.org/10.33448/rsd-v10i1.11879

Polo, M. T. y Aparicio, M. (2018). Primeros pasos hacia la inclusión: actitudes hacia la discapacidad de docentes en educación infantil. Revista de Investigación Educativa, 36(2), 365-379. https://doi.org/10.6018/rie.36.2.279281

Prado, R. A. (2018). La socioformación: un enfoque de cambio educativo. Revista iberoamericana de educación, 76(1), 57-82. https://doi.org/10.35362/rie7612955

Rappoport, S., Sandoval, M., Simón, C. y Echeita, G. (2019). Understanding inclusion support systems: three inspiring experiences. Culture and Education, 31(1), 120-151. https://doi.org/10.1080/11356405.2019.1565250

Rikkert, M. van der Lans, Wim, J. C. M. van de Grift, y K. van Veen, (2018). Developing an Instrument for Teacher Feedback: Using the Rasch Model to Explore Teachers' 
Development of Effective Teaching Strategies and Behaviors. The Journal of Experimental Education, 86(2), 247-264. https://doi.org/10.1080/00220973.2016.1268086

Rodríguez-Gómez, D., Armengol, C. y Meneses, J, (2017). La adquisición de las competencias profesionales a través de las prácticas curriculares de la formación inicial de maestros. Revista de Educación, (376), 229-251. https://doi.org/10.4438/1988592X-RE-2017-376-350

Rodríguez, A. y Álvarez, E. (2017). Presentación del monográfico Educación inclusiva: avances desde la reflexión, la práctica y la investigación. Aula Abierta, (46), 5-8. https://goo.gl/DwrQrs

Rodríguez, A. y Caurcel, M. (2019). Aproximación cualitativa del escudriño en Psicología educativa. Propósitos y Representaciones, 7(1), 01-09. http://dx.doi.org/10.20511/ pyr2019.v7n1.301

Rodríguez, G., Ibarra, M. S. y Cubero, J. (2018). Competencias básicas relacionadas con la evaluación. Un estudio sobre la percepción de los estudiantes universitarios. Educación XX1, 21(1), 181-208. https://doi.org/10.5944/educXX1

Romera, F. (2016). Estudio sobre las organizaciones inteligentes en Andalucía. Revista Fuentes, 18(1), 15-32. http://dx.doi.org/10.12795/revistafuentes.2016.18.1.01

Sagredo, E. J., Bizama, M. P. y Careaga, M. P. (2020). Gestión del tiempo, trabajo colaborativo docente e inclusión educativa. Revista Colombiana de Educación, 1(78), 343-360. http://doi.org/10.17227/rce.num78-9526

Sanahuja, A., Moliner, O. y Moliner, L. (2020a). Organización del aula inclusiva: ¿Cómo diferenciar las estructuras para lograr prácticas educativas más efectivas? Revista Complutense de Educación, 31(4), 497-506. https://doi.org/10.5209/rced.65774

Sanahuja, A., Benet, A. y Nieto, R. (2020b). Training on inclusion in higher education: prepared to work within the inclusive model? Culture and Education, 32(1), 78-105. https:// doi.org/10.1080/11356405.2019.1705595

Sánchez-Contreras, M. L. (2019). Taxonomía Socioformativa: Un Referente para la Didáctica y la Evaluación. Forhum International Journal of Social Sciences and Humanities, 1(1), 100-115. https://doi.org/10.35766/jf19119

Sandoval, M., Simón, C. y Márquez, C. (2019). ¿Aulas inclusivas o excluyentes?: barreras para el aprendizaje y la participación en contextos universitarios. Revista Complutense de Educación, 30(1), 261-276. https://doi.org/10.5209/rced.57266

Santoyo, D. S. (2019). Enfoque del Desarrollo Social Sostenible y la Gestión del Talento Humano en el contexto de la Socioformación. Ecocience International Journal, 1(1), 86-92. https://doi.org/10.35766/je191112

SEP-Autoridad Educativa Federal en la Ciudad de México. (2018). Guía Operativa para la Organización y Funcionamiento de los Servicios de Educación Inicial, Básica, Especial y para Adultos de Escuelas Públicas en la Ciudad de México. 2018-2019. SEP. https://bit. ly/3opKqN1

SEP-Instituto de la Educación Básica del Estado de Morelos. (2018). Modelo de atención para los servicios de educación especial en el Estado de Morelos. SEP.

SEP. (2018). Estrategia de equidad e inclusión en la educación básica: para alumnos con discapacidad, aptitudes sobresalientes y dificultades severas de aprendizaje, conducta y comunicación. SEP. https://bit.ly/2M7vBCb 
Symeonidou, S. (2017). Initial teacher education for inclusion: a review of the literature. Disability \& Society, 32(3), 401-422. http://dx.doi.org/10.1080/09687599.2017.1298992 Tobón, S. y Luna-Nemecio, J. (2021). Proposal for a new talent concept based on socioformation. Educational Philosophy and Theory, 53 (1), 21-33. https://doi.org/10.1080/ 00131857.2020.1725885

Tourón, J., Martín, D., Navarro, E., Pradas, S. y Íñigo, V. (2018). Validación de constructo de un instrumento para medir la competencia digital docente de los profesores (CDD). Revista Española de Pedagogía, 76(269), 25-54. https://doi.org/10.22550/ REP76-1-2018-02

Veloquio, G. (2016). La formación permanente de los docentes, ante el desafío de atender a la diversidad educativa. Revista Nacional e Internacional de Educación Inclusiva, 9(2), 144-154. https://bit.ly/39vt912

Verdeja, M. (2018). Ideas centrales del pensamiento pedagógico político de Paulo Freire: dimensiones de análisis. Revista Fuentes, 20(1), 43-56. http://dx.doi.org/10.12795/ REVISTAFUENTES.2018.v20.i1.03

Zapico, M. H., Martínez, E. y Montero, M. L. (2017). Demandas sociales y formación inicial del profesorado: ¿un callejón sin salida? Revista de Currículum y Formación del Profesorado, 21(1), 80-102. http://hdl.handle.net/10481/47482

Fecha de recepción: 9 de septiembre de 2020.

Fecha de revisión: 1 de octubre de 2020.

Fecha de aceptación: 11 de febrero de 2020. 